\title{
Modelling technique trend (interatomic potential) to study the mineral surfaces: A Review
}

\section{Asmaa Y. Al-Baitai ${ }^{*}$, Saifaldeen M. Abdalhadi²}

1- Department of Chemistry, College of science, Al-Nahrain University, Baghdad, Iraq (( dr asmaaalbayati@yahoo.com)

2- Department of remote Sensing, College of remote Sensing and Geophysics, Al-Karkh University of science, Baghdad, Iraq

\begin{tabular}{|c|c|}
\hline Article Information & Abstract \\
\hline $\begin{array}{l}\text { Received: } 11 / 05 / 2020 \\
\text { Accepted: } 27 / 06 / 2020\end{array}$ & $\begin{array}{l}\text { Computational chemistry is another branch of chemistry that can be } \\
\text { used to model the material which is based on the mathematical methods } \\
\text { and combined that with the theories of the quantum mechanics. }\end{array}$ \\
\hline Keywords: & $\begin{array}{l}\text { However, in this filed there are two different techniques or categories, } \\
\text { classical interatomic potential and the electronic structure methodology. }\end{array}$ \\
\hline $\begin{array}{l}\text { Atomistic simulation } \\
\text { methods, Interatomic } \\
\text { Potential, Surface, Gulp } \\
\text { and METADISE. }\end{array}$ & $\begin{array}{l}\text { The aim of this paper is to describe how can modelling the structures } \\
\text { and energetics of surface and interface processes of minerals surface, } \\
\text { using the classical atomistic simulation methods. We will illustrate the } \\
\text { types of potentials and some of Codes (Gulp and METADISE) which is } \\
\text { needed to do these calculations to elucidate the structures and stabilities } \\
\text { as well. }\end{array}$ \\
\hline
\end{tabular}

\section{Introduction:}

Understanding the structure of minerals surface is important due to used them in different fields such as, corrosion, catalysis, diffusion, and crystal growth, electronic and ionic conduction [1-6]. The using of experiments techniques to investigate the most stable structure was frequently difficult. Therefore, the modelling of these systems is important via using the complementary tool of simulation methods to allow us to understand their behaviour such as the defects [1, 7-9].

Firstly, the structure and properties of surfaces of ionic solid was studied using the classical atomistic simulation methods by the work of Tasker [7] and Mackrodt and Stewart [10]. While the early work was limited to study the simulation of the cubic rock salt oxide surfaces which includes (MgO, $\mathrm{CaO}$ and $\mathrm{NiO}$ ) [11-13], due to the increase in power and memory computer was possible to study more complicated materials surface for example, $\mathrm{Cr}_{2} \mathrm{O}_{3}$ [14], $\mathrm{Fe}_{3} \mathrm{O}_{4}$ [15] and $\mathrm{Al}_{2} \mathrm{O}_{3}$ [16]. Thereafter the development of models for oxy-anions as, $\mathrm{CO}_{3}{ }^{2-}, \mathrm{PO}_{4}{ }^{3-}$ and $\mathrm{SO}_{4}{ }^{2-}$ were important to study the surface, for example the simulation of $\mathrm{CaCO}_{3}$ minerals $[17,18]$, also the $\mathrm{Ca}_{10}\left(\mathrm{PO}_{4}\right)_{6}(\mathrm{~F}, \mathrm{OH})_{2}[19,20]$.

Secondly, one of the main interesting research parts in computational surface science field is the surface and water interaction and that because of the dissolution processes which means the modelling of surfaces in a vacuum no longer after that be possible, but need to take 
the role of presence water [18, 21-27]. Recently, the new research works focus on the study the adsorption of some organic molecules at mineral surfaces [20, 25, 28-32].

Finally, as result of increasing the computing power and memory that has made possible to find new tools, algorithms and methods for modelling and optimization the surface using the electronic structure simulation methods, and one the of this calculation was the Density Functional Theory such as, investigation the surface structures for $\alpha$-alumina [33], and the surfaces of both $\mathrm{ZnO}$ and $\mathrm{CdS}$ [34]. There are a wide range of different materials have been modelled starting from metals for instance, InAs [35] and $\operatorname{ErSi}_{1.7}$ [36] also the oxides such as $\mathrm{SnO}_{2}, \mathrm{TiO}_{2}$ and $\mathrm{MgO}$ [37-39]. In addition to these studies, in the last few years have been using the phenomena of adsorption to study the adsorption of several small molecules on metals surfaces, for example, the $\mathrm{CO}$ on palladium [40] and nickel [41] also the adsorption of $\mathrm{Cl}_{2}$ on silver [42]. Another aspects to investigate the surface structure using the atomistic simulation methods is study the adsorption of oxide surfaces, for instance, the adsorption of both CO and water on $\mathrm{TiO}_{2}$ [43-45], $\mathrm{NH}_{3}$ on $\mathrm{MgO}$ [46], adsorption of $\mathrm{O}_{2}$ on $\mathrm{FeSbO}_{4}$ [47], and the adsorption of $\mathrm{OH}$ on hematite and maghemite [29].

More recently, the surface science starts to cover the adsorption of small molecules onto the mineral surfaces which can be provided us useful information about the molecular level understanding into complex geochemical phenomena for instance, mineralizatio of organic molecules, mineral dissolution, surface complexation [20, 25, 28-30, 48]. However, the using of these techniques, the static calculations and electronic structure molecular dynamics simulations are still limited in the number of atoms which can be treated, and later we find to describe the surface structures and its interfaces for a large systems will need to use a combination techniques of both accurate electronic structure techniques and the classical atomistic simulations and the two forms of techniques frequently show excellent quantitative agreement such as to structures and energies of the systems needed to investigate [49].

\section{1- Interatomic Potential}

The atomistic simulation methods are used to discuss the stable structure for the molecules in order to understand the host of the properties such as, physical properties, defects. This technique was built on a number of expectations, however, these forms are the Born model of solids [50], which assumes that the ions in the crystal will interact through the long-range electrostatic forces and the short-range forces, which include both the van der Waals attractions and Pauli repulsions which can be described by the following equation:

$$
E_{(i j)}=\sum_{i j} \frac{q i q j}{4 \pi \varepsilon_{0}\left(r_{i j 0}+1\right)}+\sum_{i j} \Phi_{i j}\left(r_{i j}\right)
$$

Here, the first term in equation (1) represents to the (Columbic interaction) which is the long range electrostatic interaction and the second term in the above equation show the interactions between neighbouring electron clouds, which is called the short-range interactions. 


\subsection{Ewald summation}

One of the most common simulation methods is called the Ewald summation, which is used to modelling the inorganic materials, and in this method the calculation of electrostatic energy is very important particularly in oxides materials and this can be realised via using Ewald summation [51]. However, this method depends on the calculation of potential energy using the sum of two rapidly converging series plus a constant term, and these will be one in real space and one in the reciprocal space as shown in the following equation:

$$
\mathrm{U}_{\text {Ewald }}=U^{r}+U^{m}+U^{o}
$$

Where $U^{r}$ is the real space sum, $U^{m}$ the reciprocal sum, and $U^{0}$ is constant, which is known as the self-term.

$$
\begin{aligned}
& U^{r} \frac{1}{2} \sum_{i, j}^{N} \sum_{n} q_{i} q_{j} \frac{\operatorname{erfc}\left(\propto r_{i j, n}\right)}{r_{i j, n}} \\
& U^{m}=\frac{1}{2 \pi V} \sum_{i, j}^{N} q_{i} q_{j} \sum_{m \neq 0} \frac{\exp \left(-\frac{\pi m}{\alpha}\right)^{2}+2 \pi i m\left(r_{i}-r_{j}\right)}{m^{2}} \\
& U^{o}=\frac{-\propto}{\sqrt{\pi}} \sum_{i=1}^{N} q_{i}{ }^{2}
\end{aligned}
$$

Here, $\mathrm{V}$ is the volume, $\mathrm{N}$ the number of particles, and $\mathrm{m}$ is the reciprocal space vector.

\subsection{Parry Method}

The other application of Ewald simulation method is called Parry method [52] and this method is usually used to simulate the system with two dimension only, for instance, surfaces. However, the calculate columbic energy is given by the following expression:

$U_{p}=\frac{\pi}{A}\left[-2 u_{i j} \operatorname{erf}\left(\eta u_{i j}\right)-\frac{2 \exp \left(-\eta^{2} u_{i j}^{2}\right)}{\eta \sqrt{\pi}}\right]+\sum_{k \neq 0} \frac{\exp \left(i k p_{i j}\right)}{k}\left[\exp \left(k u_{i j}\right) \operatorname{erfc}\left(\frac{k}{2 \eta}-\eta u_{i j}\right)+\right.$ $\left.\exp \left(-k u_{i}\right) \operatorname{erfc}\left(\frac{k}{2 \eta}-\eta u_{i j}\right)\right]$

Where $A$ is an area of unit cell, $\eta$ is a parameter, and it has been chosen to get the rapid convergence.

\section{2- Functions of Interatomic Potential:}

To estimate the energy and all details of the nuclear coordinates, it can by using the interatomic potential, however, the function of this potential energy was made up using the function of two body potential, where there are two positions of each two atoms, and another types are three and four body potential functions. The most important influence of the twobody interaction is including the non-bonded interactions "van der Waals attraction and 
repulsion". However, there are different types of two-body potentials as shown in the following sections.

\section{1 - Harmonic Potential}

There are different types of two body potential and the most simple is called the harmonic potential, and it's depend of the proportional of the square of the separation for two atoms as shown in the following form:

$$
U_{(i j)}=\frac{k_{i j}}{2}\left(r_{i j}-r_{0}\right)^{2}
$$

Where $k_{i j}$ is the bond force constant between atoms $\mathrm{i}$ and $\mathrm{j}$, while $r_{i j}$ is the distance between atoms $\mathrm{i}$ and $\mathrm{j}$, and $r_{0}$ is the equilibrium separation of the atoms.

\section{2 - Morse Potential}

Morse Potential is a second model of two body potential, which is routinely used to model the system that has a covalent bond. In this type of the two-body potential the calculated total energy is considered as a relative exponential to the equilibrium distance with interatomic spacing, which is given in the equation (8):

$$
U_{(i j)}=D-\left(1-\exp \left[-\alpha_{i j}\left(r_{i j}-r_{0}\right]\right)^{2}-D\right.
$$

$D$ is the energy of dissociation process, while $\alpha_{i j}$ is constant and its obtained from spectroscopic data [53].

\section{3 - Lennard -Jones Potential}

The most commonly potential model that can be used to determine the interaction for a big system, practically, the one has non-bond interactions is the Lennard -Jones Potential, which has the following expression:

$$
U_{(i j)}=\frac{A}{r_{i j}^{12}}-\frac{B}{r_{i j}^{6}}
$$

Where $A$ and $B$ are adjustable limitations.

\section{4 - Buckingham Potential}

The part of the short-range for the two-body potential functions especially for ionic or semi-ionic solids can be described by the most frequently model which is called the Buckingham potential [54], which has the following expression:

$$
U_{(i j)}=A_{i j} \exp \left(\frac{-r_{i j}}{\rho_{i j}}\right)-\frac{C_{i j}}{r_{i j}^{6}}
$$

$r^{-6}$ is van der Waals interaction. While this term $\frac{C_{i j}}{r_{i j}^{6}}$ is omitted. 


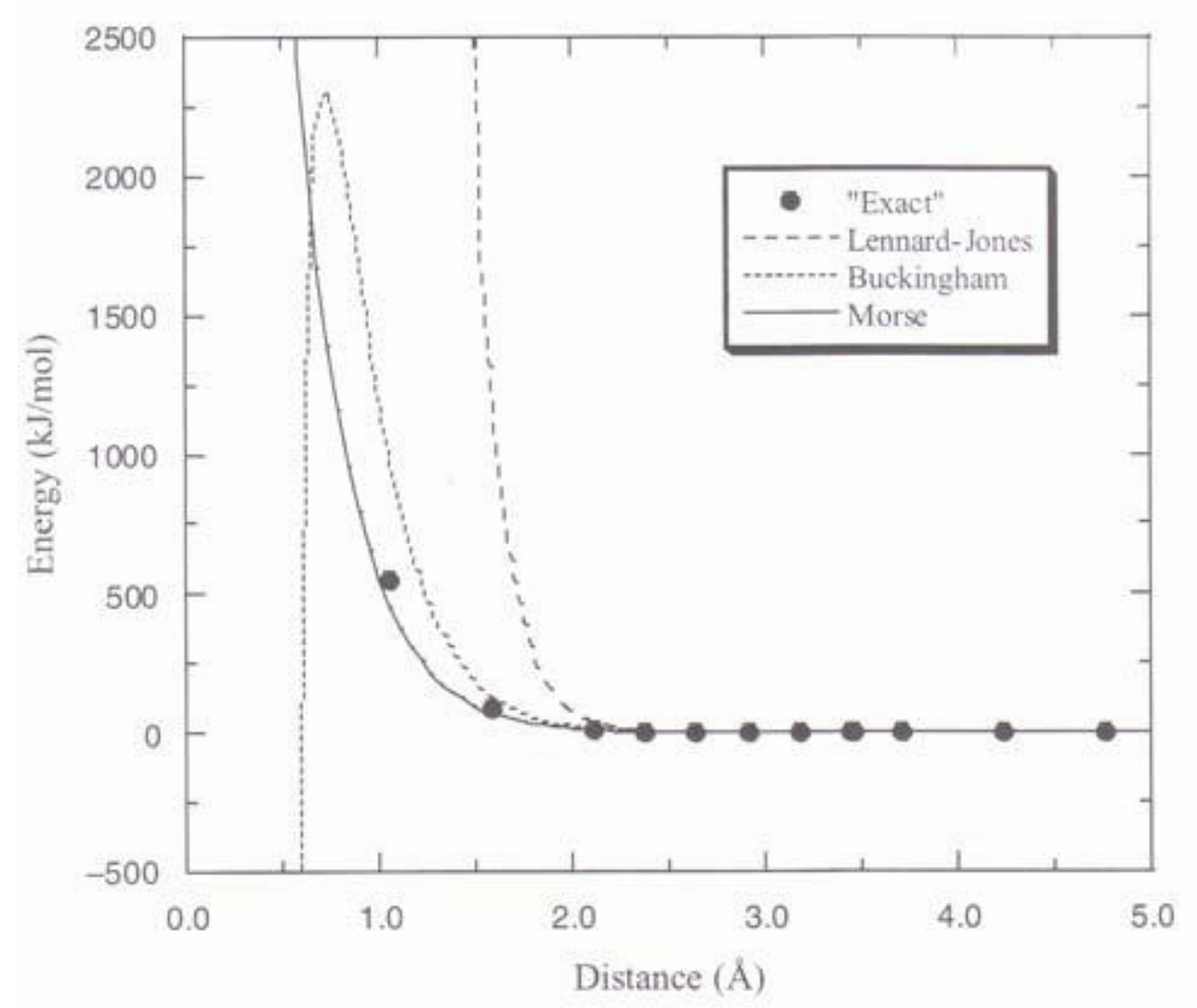

Fig. 1 Sketch of the three different interatomic potentials.

\section{5 - Three -Body Interaction}

Other impact that can effect on the calculation of energy for short range interaction is the three -body Potential, however, this kind of the potential is usually applied to describe the bending that can happen for the bond via the simulation processes especially if that system has three atoms.

$$
U\left(\theta_{i j k}\right)=\frac{k_{i j k}}{2}\left(\theta_{i j k}-\theta_{0}\right)^{2}
$$

Where $\theta_{i j k}$ is the angle between two bonds, $i-j$ and $i-k$ respectively, $k_{i j k}$ Bond -bending force and $\theta_{0}$ is the equilibrium angle, as presented bellow (Fig. 2) .

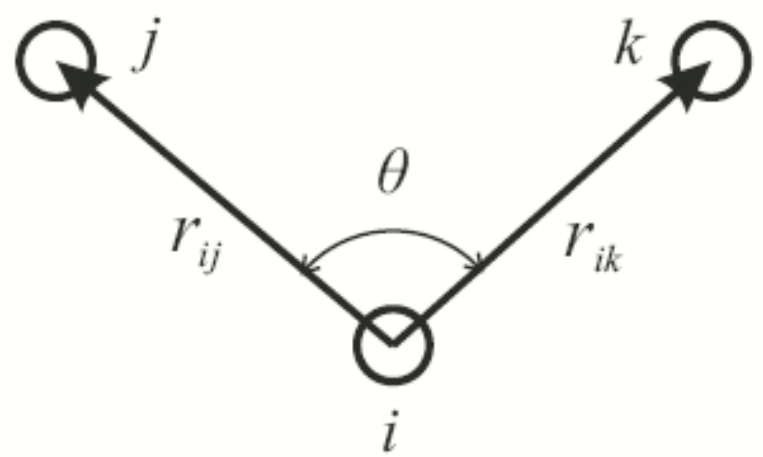

Fig. 2 Valence angle. 


\section{6 - Four -Body Interaction}

This kind of potential model can be used for simulation the molecules which are usually included four atoms, and as usually need to describe the coordination and the bond lengths and bond distances but in this case the molecule will have dihedral angle

$$
U\left(\emptyset_{i j k n}\right)=k_{i j k n}\left(1-s \cos \left(n \phi_{i j k n}\right)\right)
$$

Where the $\mathrm{k}$ is bending force and $\phi$ is the angle.

\section{3- Electronic Polarisability}

Involving the effect of polarisability in the calculations for any types of system that contains polarisable ions play an important role on the accurate of simulation calculation, for instance, when do modelling to investigate the defect or surface properties for system as water in this case, oxygen atoms which have electronic polarisability therefore it will included via using the shell model [55], and in this model is assumed that the massive core for the polarisable ion is connected to the shell via a spring as shown in fig. 3.

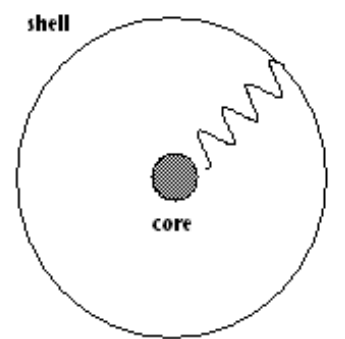

Fig. 3 Design of the shell model of the ionic polarisability.

However, the simplest mechanical treatment to calculate the electronic polarisability of the atoms $(\alpha)$ shows in the equation 13 :

$$
\propto=\frac{q^{2}}{k}
$$

Here $k$ is the force constant for the spring.

\section{4- Simulation Methods}

The modelling techniques to simulate any crystal in order to get the calculated energy at a minimum point and in this case the distances between the ions should be exactly match the distance which that experimentally perceived for the crystal structure. But if any movement that point will lead to have the configuration with higher energy and this could be managed in two ways, at constant pressure or at constant volume. When kept the pressure as constant, then will need to remove the strain effect and that would be via relaxation of each ion which is located in one unit cell. However, there are many different algorithms which could be used to find the stable structure, and the most common ones to do that are the Conjugated Gradients or Newton Raphson Methods [56, 57], but the widely used method especially to study the 
surface is Newton-Raphson and that because is more accurate but not rapidly convergent as Conjugated Gradients which depends on the first derivative.

\section{5- Simulation Codes}

There are many different codes that can be used to using to investigate the lattice crystal structure and investigate the properties such as the defect or the surface. The most common one is called Gulp and this molecular simulation program is based on interatomic potentials, and it's used for modelling the bulk structure of crystal, in this code to calculate the parameters of the cell with coordination for the optimum ion, should minimise the lattice energy of the crystal [58].

To study the dislocations, interfaces and surface structure with morphology for any system need to use another code which is called a METADISE [59] in this code will get the unrelaxed and relaxed surface structures with surface energies, and that followed Tasker style [7] when this model involves study the system with two dimensions only as in the surface. And the main point to calculate surface energies for the stable structure the dipole moment should be zero therefore, before do start our calculations have to remove the dipole moment by half of the ions which are located on the top layer of the surface of the repeat unit and shift it to the bottommost layer then will have the surface with no dipole effect. Tasker is classified the surface for three different types as bellow [7]:

a. "Type I, where the repeat unit is a charge neutral stoichiometric layer" (Fig. 4(a)).

b. "Type II, which comprise charged layers but in such a way that there is no dipole moment perpendicular to the surface" (Fig. 4(b)).

c. "Type III, where there is a dipole moment perpendicular to the surface" (Fig. 4(c)).

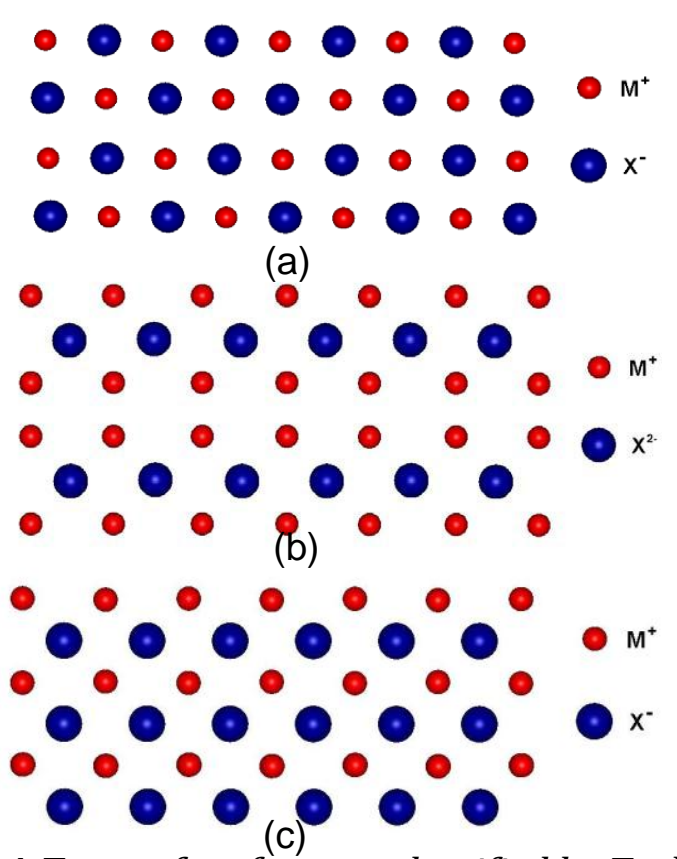

Fig. 4 Types of surfaces as classified by Tasker. 


\section{Conclusions}

In this paper we have described validity of the atomistic simulation technique via using Interatomic potential method to investigate and model a host of different types of surface structure to get the interfacial features and properties. However, the applications are discussed in this review paper show how modern modelling methods can now be useful to apply to investigate and understand the complex materials and processes, which routinely are normally difficult to study experimentally.

\section{References:}

1. Duffy, D. M. (1986). Grain boundaries in ionic crystals. Journal of Physics C: Solid State Physics, 19(23), 4393.

2. Sakaguchi, I., Yurimoto, H., \& Sueno, S. (1992). Self-diffusion along dislocations in singlecrystals Mg0. Solid state communications, 84(9), 889-893.

3. Pegg, J. T., Shields, A. E., Storr, M. T., Scanlon, D. O., \& de Leeuw, N. H. (2019). Interaction of hydrogen with actinide dioxide (111) surfaces. The Journal of chemical physics, 150(13), 134701.

4. Pegg, J. T., Shields, A. E., Storr, M. T., Scanlon, D. O., \& de Leeuw, N. H. (2019). Interaction of hydrogen with actinide dioxide (111) surfaces. The Journal of chemical physics, 150(13), 134701.

5. Olsson E, Cottom J, Aparicio-Anglès X, de Leeuw NH.2020; Combined density functional theory and molecular dynamics study of cathode material for next generation solid oxide fuel cell. Physical Chemistry Chemical Physics (Incorporating Faraday Transactions), 22: 692 DOI: $10.1039 / \mathrm{c} 9 \mathrm{cp} 04892 \mathrm{~h}$.

6. Roldan, A., \& de Leeuw, N. H. (2019). A density functional theory study of the hydrogenation and reduction of the thio-spinel Fe 3 S $4\{111\}$ surface. Physical Chemistry Chemical Physics, 21(5), 2426-2433.

7. Tasker PW.1979; The stability of ionic crystal surfaces. Journal of Physics C: Solid State Physics, 12: 4977-4984 DOI: 10.1088/0022-3719/12/22/036.

8. Puls, M. P., Woo, C. H., \& Norgett, M. J. (1977). Shell-model calculations of interaction energies between point defects and dislocations in ionic crystals. Philosophical Magazine, 36(6), 1457-1472.

9. Menkah, E. S., Dzade, N. Y., Tia, R., Adei, E., \& de Leeuw, N. H. (2019). Hydrazine adsorption on perfect and defective fcc nickel (100),(110) and (111) surfaces: A dispersion corrected DFT-D2 study. Applied Surface Science, 480, 1014-1024.

10. Mackrodt, W. C., \& Stewart, R. F. (1979). Defect properties of ionic solids. III. The calculation of the point-defect structure of the alkaline-earth oxides and CdO. Journal of Physics C: Solid State Physics, 12(23), 5015.

11. Colbourn, E. A., Mackrodt, W. C., \& Tasker, P. W. (1983). The segregation of calcium ions at the surface of magnesium oxide: theory and calculation. Journal of Materials Science, 18(7), 1917-1924.

12. Tasker, P. W., Colbourn, E. A., \& Mackrodt, W. C. (1985). Segregation of isovalent impurity cations at the surfaces of $\mathrm{MgO}$ and CaO. Journal of the American Ceramic Society, 68(2), 7480. 
13. Tasker, P. W., \& Duffy, D. M. (1984). The structure and properties of the stepped surfaces of MgO and NiO. Surface Science, 137(1), 91-102.

14. Lawrence, P. J., Parker, S. C., \& Tasker, P. W. (1988). Computer simulation studies of perfect and defective surfaces in Cr203. Journal of the American Ceramic Society, 71(8), C389.

15. Davies, M. J., Parker, S. C., \& Watson, G. W. (1994). Atomistic simulation of the surface structure of spinel. Journal of Materials Chemistry, 4(6), 813-816.

16. Mackrodt, W. C. (1989). Atomistic simulation of the surfaces of oxides. Journal of the Chemical Society, Faraday Transactions 2: Molecular and Chemical Physics, 85(5), 541-554.

17. De Leeuw, N. H., \& Parker, S. C. (2000). Modeling absorption and segregation of magnesium and cadmium ions to calcite surfaces: Introducing MgCO 3 and CdCO 3 potential models. The Journal of Chemical Physics, 112(9), 4326-4333.

18. de Leeuw, N., \& Parker, S. (1997). Atomistic simulation of the effect of molecular adsorption of water on the surface structure and energies of calcite surfaces. Journal of the Chemical Society, Faraday Transactions, 93(3), 467-475.

19. Rabone, J. A. L., \& De Leeuw, N. H. (2006). Interatomic potential models for natural apatite crystals: incorporating strontium and the lanthanides.Journal of computational chemistry, 27(2), 253-266.

20. Filgueiras, M. R. T., Mkhonto, D., \& de Leeuw, N. D. (2006). Computer simulations of the adsorption of citric acid at hydroxyapatite surfaces. Journal of crystal growth, 294(1), 6068.

21. de Leeuw, N. H., \& Parker, S. C. (1998). Surface structure and morphology of calcium carbonate polymorphs calcite, aragonite, and vaterite: an atomistic approach. The Journal of Physical Chemistry B, 102(16), 2914-2922.

22. de Leeuw, N. H., Higgins, F. M., \& Parker, S. C. (1999). Modeling the surface structure and stability of $\alpha$-quartz. The Journal of Physical Chemistry B, 103(8), 1270-1277.

23. Mkhonto, D., \& de Leeuw, N. H. (2002). A computer modelling study of the effect of water on the surface structure and morphology of fluorapatite: introducing a Ca 10 (PO 4) 6 F 2 potential model. Journal of Materials Chemistry, 12(9), 2633-2642.

24. Cooper, T. G., \& De Leeuw, N. H. (2003). A combined ab initio and atomistic simulation study of the surface and interfacial structures and energies of hydrated scheelite: introducing a CaW04 potential model. Surface science, 531(2), 159-176.

25. Cooper, T. G., \& de Leeuw, N. H. (2012). A Computer Modeling Study of the Competitive Adsorption of Water and Organic Surfactants at Surfaces of the Mineral Scheelite. Langmuir, 28(33), 12423-12423.

26. Santos-Carballal, D., Roldan, A., Grau-Crespo, R., \& de Leeuw, N. H. (2014). A DFT study of the structures, stabilities and redox behaviour of the major surfaces of magnetite Fe 30 4. Physical Chemistry Chemical Physics, 16(39), 21082-21097.

27. Roldan, A., Santos-Carballal, D., \& de Leeuw, N. H. (2013). A comparative DFT study of the mechanical and electronic properties of greigite Fe3S4 and magnetite Fe304. The Journal of Chemical Physics, 138(20), 204712.

28. de Leeuw, N. H., \& Cooper, T. G. (2004). A computer modeling study of the inhibiting effect of organic adsorbates on calcite crystal growth. Crystal growth \& design, 4(1), 123-133. 
29. Mkhonto, D., Ngoepe, P. E., Cooper, T. G., \& de Leeuw, N. H. (2006). A computer modelling study of the interaction of organic adsorbates with fluorapatite surfaces. Physics and chemistry of minerals, 33(5), 314-331.

30. Al-Baitai, A. Y. (2011). Computational studies of the interaction of pollutants with iron oxide surfaces (Doctoral dissertation, UCL (University College London)).

31. Santos-Carballal, D., Roldan, A., Dzade, N. Y., \& De Leeuw, N. H. (2018). Reactivity of CO2 on the surfaces of magnetite (Fe304), greigite (Fe3S4) and mackinawite (FeS). Philosophical Transactions of the Royal Society A: Mathematical, Physical and Engineering Sciences, 376(2110), 20170065.

32. Posada-Pérez, S., Santos-Carballal, D., Terranova, U., Roldan, A., Illas, F., \& de Leeuw, N. H. (2018). CO 2 interaction with violarite (FeNi 2 S 4) surfaces: a dispersion-corrected DFT study. Physical Chemistry Chemical Physics, 20(31), 20439-20446.

33. Manassidis, I., \& Gillan, M. J. (1994). Structure and energetics of alumina surfaces calculated from first principles. Journal of the American Ceramic Society, 77(2), 335-338.

34. Schröer, P., Krüger, P., \& Pollmann, J. (1994). Self-consistent electronic-structure calculations of the $\left(101^{-} 0\right)$ surfaces of the wurtzite compounds $\mathrm{ZnO}$ and CdS. Physical Review B, 49(24), 17092.

35. Swanston, D. M., McLean, A. B., McIlroy, D. N., Heskett, D., Ludeke, R., Munekata, H., ... \& DiNardo, N. J. (1994). Surface localized states on InAs (110). Surface science, 312(3), 361368.

36. Stauffer, L., Mharchi, A., Saintenoy, S., Pirri, C., Wetzel, P., Bolmont, D., \& Gewinner, G. (1995). Surface electronic and atomic structure of ErSi 1.7 on Si (111). Physical Review B, 52(16), 11932.

37. Goniakowski, J., Holender, J. M., Kantorovich, L. N., Gillan, M. J., \& White, J. A. (1996). Influence of gradient corrections on the bulk and surface properties of TiO 2 and SnO 2. Physical Review B, 53(3), 957.

38. Purton, J., Bullett, D. W., Oliver, P. M., \& Parker, S. C. (1995). Electronic structure and atomistic simulations of the ideal and defective surfaces of rutile. Surface science, 336(12), 166-180.

39. Kantorovich, L. N., Holender, J. M., \& Gillan, M. J. (1995). The energetics and electronic structure of defective and irregular surfaces on MgO.

40. Mijoule, C., Bouteiller, Y., \& Salahub, D. R. (1991). Density functional calculation of the vibrational stretching mode of $\mathrm{CO}$ coadsorbed with ammonia on palladium clusters. Surface science, 253(1-3), 375-385.

41. Görling, A., Ackermann, L., Lauber, J., Knappe, P., \& Rösch, N. (1993). On the coadsorption of CO and alkali atoms at transition metal surfaces: a LCGTO-LDF cluster study. Surface science, 286(1-2), 26-45.

42. De Leeuw, N. H., Nelson, C. J., Catlow, C. R. A., Sautet, P., \& Dong, W. (2004). Densityfunctional theory calculations of the adsorption of $\mathrm{Cl}$ at perfect and defective $\mathrm{Ag}$ (111) surfaces. Physical Review B, 69(4), 045419.

43. Pacchioni, G., Ferrari, A. M., \& Bagus, P. S. (1996). Cluster and band structure ab initio calculations on the adsorption of $\mathrm{CO}$ on acid sites of the TiO2 (110) surface. Surface Science, 350(1-3), 159-175.

44. Goniakowski, J., \& Gillan, M. J. (1996). The adsorption of H2O on TiO2 and SnO2 (110) studied by first-principles calculations. Surface Science, 350(1-3), 145-158. 
45. Shields, A. E., Santos-Carballal, D., \& de Leeuw, N. H. (2016). A density functional theory study of uranium-doped thoria and uranium adatoms on the major surfaces of thorium dioxide. Journal of Nuclear Materials, 473, 99-111.

46. Pugh, S., \& Gillan, M. J. (1994). The energetics of NH3 adsorption at the MgO (001) surface. Surface science, 320(3), 331-343.

47. Grau-Crespo, R., Catlow, C. R. A., \& de Leeuw, N. H. (2007). A computer modeling study of redox processes on the FeSb04 (100) surface. Journal of Catalysis, 248(1), 77-88.

48. Posada-Pérez, S., Viñes, F., Valero, R., Rodriguez, J. A., \& Illas, F. (2017). Adsorption and dissociation of molecular hydrogen on orthorhombic $\beta$-Mo2C and cubic $\delta$-MoC (001) surfaces. Surface Science, 656, 24-32.

49. de Leeuw, N. H., \& Cooper, T. G. (2003). A computational study of the surface structure and reactivity of calcium fluoride. Journal of Materials Chemistry, 13(1), 93-101.

50. Born, M., \& Huang, K. (1954). Dynamical theory of crystal lattices. Clarendon press.

51. Ewald, P. (1921). Evaluation of optical and electrostatic lattice potentials. Ann. Phys., 64, 253-287.

52. Parry, D. E. (1975). The electrostatic potential in the surface region of an ionic crystal. Surface Science, 49(2), 433-440.

53. Morse, P. M. (1929). Diatomic molecules according to the wave mechanics. II. Vibrational levels. Physical review, 34(1), 57.

54. Buckingham, R. A. (1938). The classical equation of state of gaseous helium, neon and argon. Proceedings of the Royal Society of London. Series A. Mathematical and Physical Sciences, 168(933), 264-283.

55. Dick Jr, B. G., \& Overhauser, A. W. (1958). Theory of the dielectric constants of alkali halide crystals. Physical Review, 112(1), 90.

56. Leach AR. Molecular Modelling,Principles and Applications. Harlow Addison Wesley Ongman ltd. 1996.

57. Jensen F. Introduction to Computational Chemistry. Denmark: John Wiley and Sons. 1999.

58. Gale, J. D., \& Rohl, A. L. (2003). The general utility lattice program (GULP). Molecular Simulation, 29(5), 291-341.

59. Watson GW, Kelsey ET, de Leeuw NH et al.1996; Atomistic simulation of dislocations, surfaces and interfaces in Mg0. Journal of the Chemical Society, Faraday Transactions, 92: 433-438 DOI: 10.1039/FT9969200433. 
|RAD|

Academic Scientific Journals
Samarra Journal of Pure and Applied Science

www.sjpas.com

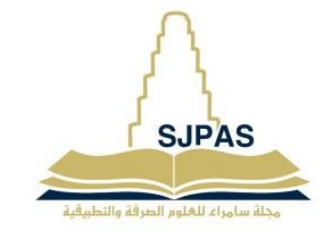

ISSN:2663-7405

اتجاه ثقنية النمذجة (الإمكانات البينية) لار اسة الأسطح المعدنية: مر اجعة

اسماء يحيى ابراهيم رسول1*، سيف الدين موفق عبد الهادي2

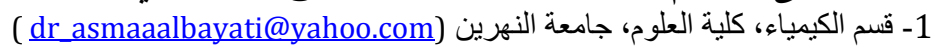

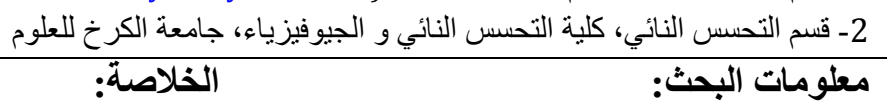

الكيمياء الحاسوبية هي فرع آخر من الكيمياء التي يمكن استخدامها لندذجة

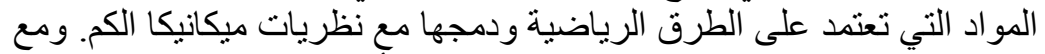

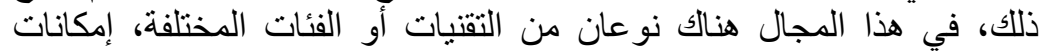

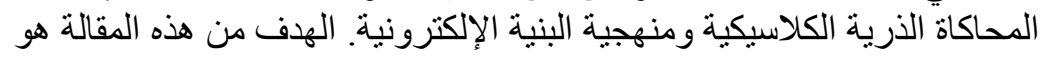

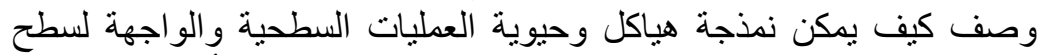

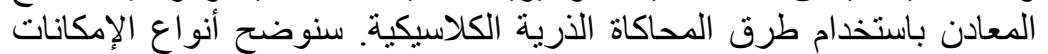
وبعض الثفرات (METADISE و Gul) التي تحتاج إلى القيام بهذه الحسابات النيات

$$
\text { لتوضيح الهياكل والاستقر ار أيضاً. }
$$

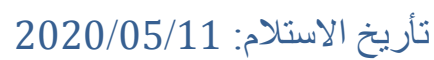

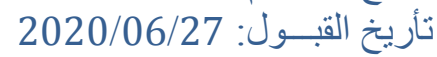

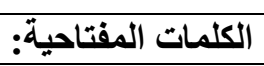

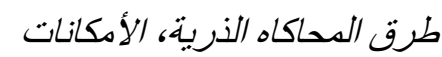
البينيه ،السطح ،شفرة Gulp ، شفره METADISE 